\title{
Chitosan-Based Layer-by-Layer Assembly: Towards Application on Quality Maintenance of Lemon Fruits
}

\author{
Fangyuan Chen, ${ }^{1}$ Jinglin Zhang, ${ }^{1}$ Cunkun Chen, ${ }^{2}$ M. G. Gloire Martha Kowaleguet, ${ }^{1}$ \\ Zhaojun Ban $\mathbb{D}^{1},{ }^{1}$ Lifeng Fei, ${ }^{1}$ and Chengchen $\mathrm{Xu}^{1}$ \\ ${ }^{1}$ School of Biological and Chemical Engineering, Zhejiang University of Science and Technology, \\ Zhejiang Provincial Key Laboratory of Chemical and Biological Processing Technology of Farm Products, \\ Zhejiang Provincial Collaborative Innovation Center of Agricultural Biological Resources Biochemical Manufacturing, \\ Hangzhou 310023, China \\ ${ }^{2}$ Tianjin Key Laboratory of Postharvest Physiology and Storage of Agricultural Products, \\ National Engineering Technology Research Center for Preservation of Agriculture Product, Tianjin 300384, China
}

Correspondence should be addressed to Zhaojun Ban; banzhaojun@zust.edu.cn

Received 28 October 2019; Accepted 15 November 2019; Published 18 February 2020

Academic Editor: Gyorgy Szekely

Copyright () 2020 Fangyuan Chen et al. This is an open access article distributed under the Creative Commons Attribution License, which permits unrestricted use, distribution, and reproduction in any medium, provided the original work is properly cited.

\begin{abstract}
We fabricated a novel chitosan-carboxymethyl cellulose (CMC) layer-by-layer assembly system to facilitate the postharvest quality of the fresh produce. Fourier transform infrared spectroscopy (FTIR), TA-XT2 texture analyzer, water vapor permeability (WVP) analyzer, and scanning electron microscopy (SEM) were applied to compare the properties of chitosan and layer-by-layer assembly. The strategy involved the optimization of water vapor permeability, puncture strength, and elasticity properties of multiplayer polymer coating. Results showed that the lemon (Citrus limon (L.) Burm. f.), coated by chitosan-CMC layer-by-layer assembly, displayed significantly higher lemon firmness and vitamin $\mathrm{C}$ content with excellent morphology, as well as inhibited weight loss and flesh browning. This study could provide support for quality maintenance in the fruit and vegetable industry and make a significant contribution to the utilization of the natural polysaccharide as a viable resource.
\end{abstract}

\section{Introduction}

Recently, due to the increasing awareness of human health and environment pollution issues, the development of natural biodegradable polymers for the quality maintenance of fresh produce has been increasingly attractive [1]. Natural polysaccharides have been proved to be promising natural products and widely used as the edible coating of fresh fruits and vegetables [2]. Polysaccharide edible coatings are based on edible and biodegradable materials since they are sustainable, plentiful, environmental friendly, and biocompatible and have low toxicity, which meets the demand for human health free of chemical residues and environmental concerns [3].

Recently, the research on green and sustainable polymers has been increasingly attractive, such as alginate [4], polarclean [5], bamboo [6], cellulose [7], Tamisolve [8], and biocoatings [9]. Chitosan, the biodegradable polymer made from the deacetylation of natural polysaccharide chitin [10], exhibits the intrinsic antimicrobial activity and has been widely utilized in fresh produce [11]. Chitosan-based edible coating, due to its selective permeability to $\mathrm{O}_{2}$ and $\mathrm{CO}_{2}$ and excellent film-forming capacity [12], was demonstrated to be effective in inhibiting the decay development and in maintaining the quality of fresh produce [13]. Additionally, carboxymethyl cellulose (CMC) is the anticipated material due to its nontoxicity, biodegradability, and good filmprocessing properties [14].

Layer-by-layer (LBL) is a novel nanoscale approach, which mainly leverages the electrostatic deposition of charged materials (such as the nanoparticles, polymers, and polyelectrolytes) onto the assembly surface $[15,16]$. 
Additionally, other charged materials, such as DNA, proteins, polysaccharides, and nanoparticles, could be used in the LBL deposition approach, which could be used in combination with one another to provide various LBL assemblies [17]. In recent years, the LBL electrostatic deposition approach was applied to prepare biogradable edible coatings which resulted in the notable quality improvement of the fresh produce [18]. Multilayered LBL edible coating, based on pectin and chitosan, was proved to prolong the shelf life of fresh-cut papaya [19]. LBL edible coating, made of alginate and chitosan, was reported to notably improve the microbial and physiological attributes of fresh-cut melon [20]. Lemon (Citrus limon (L.) Burm. f.) is the third most top species among all citrus worldwide after orange and mandarin and is cultivated in several countries all over the world [21]. The mature season of the lemon fruit is averagely from August to December in every year. Lemon fruit is abundant in carotenoids, flavonoids, minerals, vitamins, essential oils, and dietary fibres. The valuable biological properties, antioxidant, and free radical scavenging potentials, as well as the health beneficial effects of lemon have been abundantly been evident in several studies; And, also it was proved that the antimicrobial and antiinflammatory properties of lemon contributed to lowering the risk of cardiovascular disorders and certain types of cancer [22-25]. Therefore, it is used worldwide not only as a fresh ready-to-eat fruit, but also as ingredients in beverages, desserts, salads, and many meat and vegetable dishes and even herbs. Nevertheless, the major postharvest loss of fresh lemons resulted from the physiological disorders, weight loss, and fungal infection, which eventually lead to the commercial revenue losses, including nutrients loss, water loss, and decay development during storage and transportation [25]. The limited application of chemical residues and urgent demand of natural biodegradable materials motivated the new breakthrough in the industry of fresh produce such as lemon.

The efficacy of a chitosan-CMC LBL assembly, formed by CMC and chitosan, on postharvest quality maintenance of the lemon fruit was evaluated in the present study. The characteristic properties, including thickness, water vapor permeability (WVP), puncture strength (PS), and elasticity of LBL assembly, were investigated, and the representative quality attributes of the lemon fruit, including weight loss, total soluble solid (TSS), and titratable acidity (TA), were studied. This study may promote the application of CMCchitosan or other polysaccharides on the postharvest quality maintenance of the fresh produce.

\section{Materials and Methods}

2.1. Materials. Chitosan powder (molecular weight: $161.16 \mathrm{kDa}$; degree of deacetylation 95\%) have been purchased from Zhejiang Golden Shell Pharmaceutical Co., Ltd. (Yuhuan city, Zhejiang province, China). Glacial acetic acid and oxalic acid dihydrate of analytical grade have been purchased from Shanghai Aladdin Bio-Chem Technology Co., Ltd. (Shanghai, China). Ascorbic acid and 2,6dichlorophenolindophenol sodium salt and CMC of analytical grade (molecular weight $242.16 \mathrm{kDa}$ ) have been purchased from Shanghai Runjie Chemical Reagent Co., Ltd. (Shanghai, China). Lemon fruits were hand-harvested from the commercial orchard (Quzhou city, Zhejiang province, China). After harvest, the fruits were transferred to the laboratory in $2 \mathrm{~h}$, manually sorted into uniform fruit size, and without any pest, or mechanical damage. All experiments were repeated three times for the reproducibility of the materials and the performance.

2.2. Preparation of Chitosan-CMC Assembly. Chitosan was dissolved in the acetic acid solution $(1.0 \%, \mathrm{v} / \mathrm{v})$ to make the chitosan solution $(1.5 \%, \mathrm{w} / \mathrm{v})$. CMC solution $(1.5 \%, \mathrm{w} / \mathrm{v})$ was prepared by dissolving CMC-sodium salt in sterilized water. The chitosan and CMC solutions were heated at $40^{\circ} \mathrm{C}$ and stirred for $20 \mathrm{~min}$ until absolutely dissolved. The chitosanCMC LBL assembly was prepared by $1.5 \%$ chitosan and $1.5 \%$ $\mathrm{CMC}$ solution, and the $\mathrm{pH}$ was adjusted to $\mathrm{pH}$ 6.3. The resulting LBL assembly was air-dried and homogenously distributed in a flat plate.

2.3. Properties of Chitosan-CMC Assembly. Fourier transform infrared spectroscopy (FTIR), coating mechanical properties, and water vapor permeability were measured according to the methodology proposed by Poverenov et al. [26].

2.3.1. Mechanical Properties. The thickness of the assembly was determined using the quartz crystal microbalance (QCM). The mechanical properties of the LBL assembly were determined by the TA-XT2 Texture Analyzer (Shanghai, China) with the stainless cylinder probe TA-52 ( $2 \mathrm{~mm}$ in diameter) at a speed of $1.0 \mathrm{~mm} \mathrm{~s}^{-1}$. The puncture strength (PS) was measured by dividing the maximum force needed to break the assembly by the thickness, and the elasticity was defined as a distance that the assembly stretched before being broken.

2.3.2. Fourier Transform Infrared Spectroscopy (FTIR). The FTIR spectra of the LBL assembly were obtained by recording the spectra from $400 \mathrm{~cm}^{-1}$ to $4,000 \mathrm{~cm}^{-1}$, with the resolution of $4 \mathrm{~cm}^{-1}$ and 100 scans in average.

2.3.3. Water Vapor Permeability (WVP). The WVP was determined according to the ASTM E-96 method (2005). The beaker full with $10 \mathrm{~mL}$ of distilled water was sealed with the assembly placed in desiccators containing dry silica gel $\left(50 \% \mathrm{RH} ; 23^{\circ} \mathrm{C}\right)$. The beaker was allowed for $2 \mathrm{~h}$ to reach the equilibrium state and weighed every $8 \mathrm{~h}$. The water vapor transmission rate (WVTR, $\mathrm{gh}^{-1} \mathrm{~m}^{-2}$ ) was calculated by plotting the weight loss versus time in a linear regression $(r \geq 0.99)$ and dividing the slope by the exposed area of assembly $\left(\mathrm{m}^{2}\right)$ :

$$
\mathrm{WVP}=\frac{\mathrm{WVTR} \times L}{\Delta P},
$$


where $L$ is the mean of assembly thickness $(\mathrm{mm})$ and $\Delta P$ is the partial water vapor pressure difference $(\mathrm{kPa})$ across the two sides of the assembly.

2.3.4. Scanning Electron Microscopy (SEM). The morphology of the LBL assembly was examined using a field emission SEM operated at $10 \mathrm{kV}$. The samples were mounted on metal stubs and coated with gold using a Polaron sputter coater.

\subsection{LBL Assembly Coating Study. Lemon (Citrus limon (L.)} Burm. f.) fruits were randomly divided into three groups. Then, the lemons were immersed in distilled water (control, CT), 1.5\% chitosan, and chitosan-CMC LBL assembly (LBL) for $5 \mathrm{~min}$. After completely air-dried, the lemons were stored in polyethylene terephthalate clamshell containers at $0^{\circ} \mathrm{C}$ for 20 days. Lemon samples were frozen in liquid nitrogen for later investigation of quality attributes. Three biological replications were carried out in the whole experiment.

\subsection{Lemon Quality Attributes}

2.5.1. Weight Loss. The results of weight loss were determined from 30 randomly selected lemons:

$$
W(\%)=\frac{m_{0}-m_{1}}{m_{0}} \times 100 \%,
$$

where $W$ is the mean weight loss, $m_{0}$ is the initial fruit weight before storage $(\mathrm{g})$, and $m_{1}$ is the weight of the fruit after storage $(\mathrm{g})$.

2.5.2. Lemon Firmness. Textural properties of the lemon fruit were assessed using the puncture test with a TA-XT2i Texture Analyzer. The maximum force required to puncture the lemon was recorded, and the ATA-52 5-mm diameter stainless cylinder probe at a speed of $0.5 \mathrm{~mm} \mathrm{~s}^{-1}$ was used for penetration to a depth of $10 \mathrm{~mm} \mathrm{[20].}$

2.5.3. Lemon Vitamin C. Determination of vitamin C content in lemon was determined by the 2,6-dichloroindophenol titrimetric method. The lemon extract was prepared by maceration using $1.0 \%$ oxalic acid $\left(\mathrm{C}_{2} \mathrm{H}_{2} \mathrm{O}_{4}\right)$, filtered, and titrated with 2,6-dichloroindophenol until the pink color persisted for 15-20 s [27]. The vitamin C content was presented as $\mathrm{mg}$ per $100 \mathrm{~g}$ of fresh weight.

2.5.4. Lemon Color. The lemon peel color of five fruits for each treatment was evaluated with a Chroma Meter (CR400).

2.5.5. Lemon Morphology and Microstructure. Five fruits were randomly selected from each group, and both the whole fruit and cross-sectional lemons were taken. $1 \mathrm{~cm}^{2}$ of size and a thickness of $1 \mathrm{~mm}$ of the lemon epidermis was cut into four small pieces, soaked in $2.5 \%$ formaldehyde solution at $4^{\circ} \mathrm{C}$ for $12 \mathrm{~h}$, and rinsed three times with $0.2 \mathrm{M}$ phosphate buffer (PBS) and was then fixed in $2 \%$ osmium acid for $1 \mathrm{~h}$, following by rinsing three times with PBS. After rinsing, the samples were successively soaked in $30 \%, 50 \%, 70 \%, 80 \%$, $90 \%$, and $95 \%$ ethanol for each 15 min to dehydrate and were then dehydrated twice with absolute ethanol for $20 \mathrm{~min}$. The microstructure images were obtained after the samples were mounted on metal stubs and coated with gold.

2.5.6. Total Soluble Solid (TSS) and Titratable Acidity (TA). Five lemons were randomly selected in each treatment and squeezed with four layers of gauze. TSS and TA contents of lemon juice were determined by PAL-BX/ACID F5.

2.6. Statistical Analysis. All data were expressed as mean$s \pm$ standard deviations (SD) from three technical and biological replications. Microsoft Office Excel was used to calculate means and SD values. One-way analysis of variance (ANOVA) with a 95\% confidence interval of the data was accomplished using SPSS 23.0 (SPSS Inc., Chicago, IL, USA). A Tukey-Kramer test was utilized when significant differences $(p<0.05)$ were detected. The data were analyzed and graphically plotted using Origin 8 software (OriginLab Software Inc. Hampton, Massachusetts, USA).

\section{Results and Discussion}

3.1. Assembly Properties. The physical properties of the chitosan and chitosan-CMC LBL assembly are presented in Table 1. It is noted that, in spite of the greater thickness, the water vapor permeability of the LBL assembly was significantly (1.74 times) greater than that of chitosan $(p<0.05)$, in agreement with their higher hydration level. The phenomenon was presumably related to the swelling behavior of the chitosan coating in the humid atmosphere, or related to the crosslinking between CMC and chitosan which results in a formation of a more loosely packed poriferous matrix rather than of a denser one and enlarges the intermolecular space and promotes the transport of water molecules in the assembly structure. It was consistently reported that the stratified structure and linear increase in the absorbance verified a linear increase in coating thickness [28]. In addition, the mechanical properties of the LBL assembly were significantly improved, in terms of both strength and elasticity $(p<0.05$, Table 1$)$. The physical properties of the LBL assembly are vitally important to the further application in the fresh produce. It has been demonstrated that from the SEM images in Figure 1, the chitosan showed a smooth and uniform surface and the LBL deposition resulted in the drastic alteration in the coating morphology and the crosssectional structure. Microstructure indicated the tight connection between chitosan and CMC.

The crosslinking structure and FTIR spectra of chitosan and chitosan-CMC LBL assembly are shown in Figure 2. It was proved that $1,570 \mathrm{~cm}^{-1}$ and $3,000 \sim 3,500 \mathrm{~cm}^{-1}$ contributed to the characteristic bands of chitosan. Results revealed that the process of chitosan ethylation did not break the representative structure of the indigenous chitosan molecule. The absorption band at $1603 \mathrm{~cm}^{-1}$ was attributed to $\mathrm{COO}^{-}$stretching vibration; additionally, the $1086 \mathrm{~cm}^{-1}$ 
TABLE 1: Thickness, water vapor permeability (WVP), puncture strength (PS), and elasticity of chitosan and chitosan-CMC LBL assembly.

\begin{tabular}{lcccc}
\hline & Thickness $(\mu \mathrm{m})$ & WVP $\left(\mathrm{g} \mathrm{mm} / \mathrm{kPa}^{-1} \mathrm{hm}^{-2}\right)$ & PS $(\mathrm{N} / \mathrm{mm})$ & Elasticity $(\mathrm{mm})$ \\
\hline Chitosan & $26.3 \pm 7.2^{\mathrm{b}}$ & $47.36 \pm 0.00^{\mathrm{b}}$ & $252 \pm 35^{\mathrm{a}}$ & $3.17 \pm 0.52^{\mathrm{a}}$ \\
LBL assembly & $43.5 \pm 5.1^{\mathrm{a}}$ & $82.55 \pm 4.64^{\mathrm{a}}$ & $314 \pm 48^{\mathrm{a}}$ & $3.09 \pm 0.25^{\mathrm{a}}$ \\
\hline
\end{tabular}

Different letters indicated significant difference at $p<0.05$.

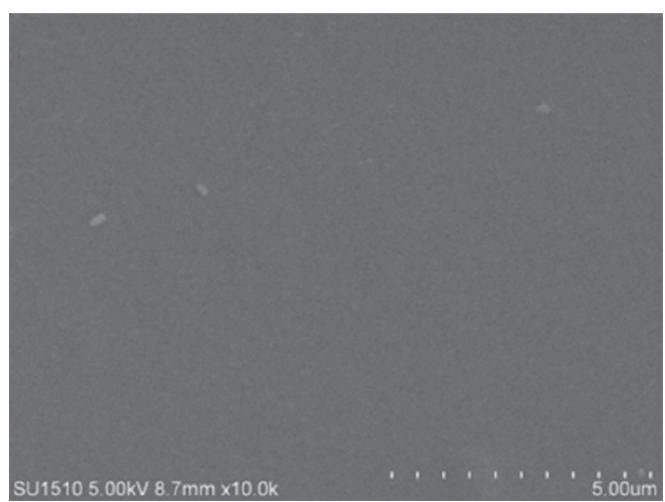

(a)

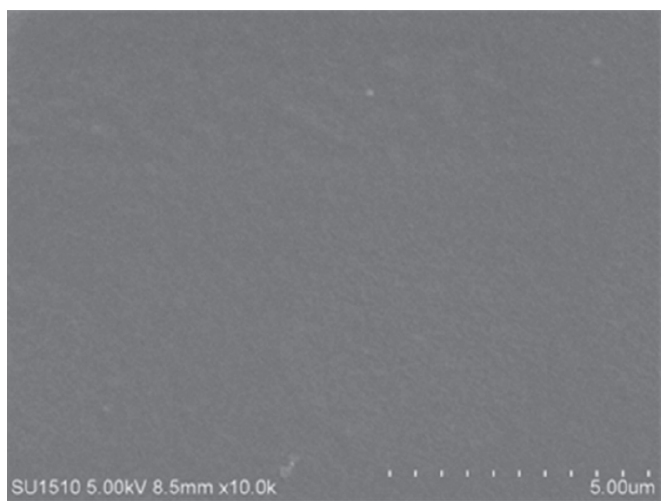

(c)

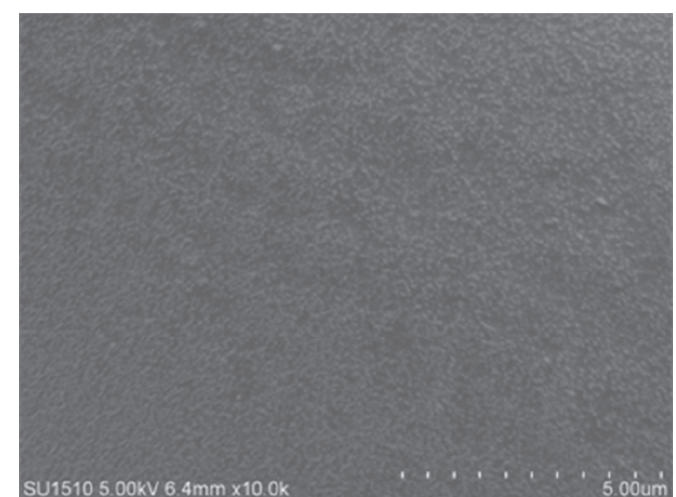

(b)

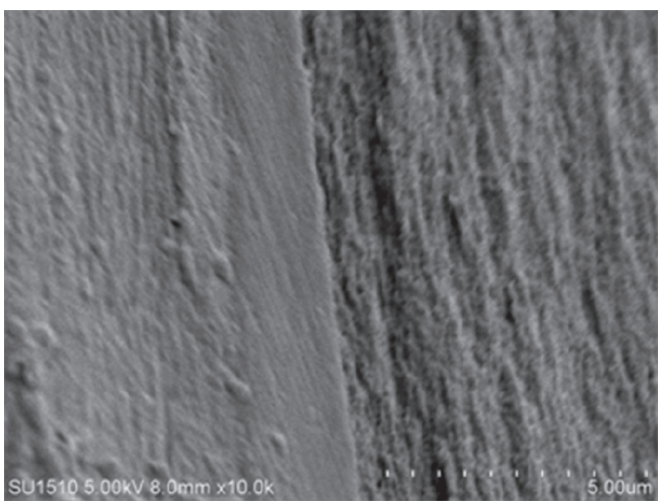

(d)

FIGURE 1: SEM images of cross section and vertical section of chitosan ((a) and (b), respectively) and chitosan-CMC LBL assembly ((c) and (d), respectively).

contributed to the $\mathrm{C}-\mathrm{O}$ stretching vibration. Results demonstrated that the characteristic position of the absorption peaks of the assembled LBL was basically consistent with the chitosan and CMC, indicating that the characteristic functional groups of the two polysaccharides were consistent with the crosslinking structure.

3.2. Lemon Quality Attributes. With regard to the weight loss, it was observed that the chitosan-CMC LBL assembly has effectively been beneficial to the quality maintenance of the lemon fruit (Figure 3(a)). Results showed that the weight loss of lemon was significantly inhibited by the LBL assembly, in comparison to the monolayer chitosan and control $(p<0.05)$. The benefit of the LBL assembly on fruit weight loss probably resulted from the increased WVP value than chitosan. The layer-by-layer coating helped pores sealing and alleviated the water loss of the lemon peel, thus improving the postharvest quality and shelf life of the fresh lemon fruit. Firmness is an important basic attribute for evaluation of fruit quality, which is widely used for quality supervision of the fresh produce during storage and transportation. It can be shown from Figure 3(b) that the lemon firmness was significantly increased by the LBL assembly after storage for 20 days $(p<0.05)$, followed by chitosan and control.

The regulation of TSS and TA content reflects the taste of the lemon fruit in response to the LBL assembly and chitosan coating. It can be seen from Figure 3(c) that, after 20 days of storage, the average content of lemon TSS in the control group was significantly higher than that in the other two groups, and the overall value was above $7.5 \%(p<0.05)$. It might be from the significant inhibition of the respiration rate of the lemon fruit, and from the reduction of the nutrient decomposition, especially starch and other polysaccharides, by the exogenous application of both LBL assembly and monolayer chitosan $(p<0.05)$. There was no significant difference in the content of lemon TSS between monolayer and layer-by-layer treatments $(p>0.05)$. It was consistently found that the chitosan coating had no significant effect on 


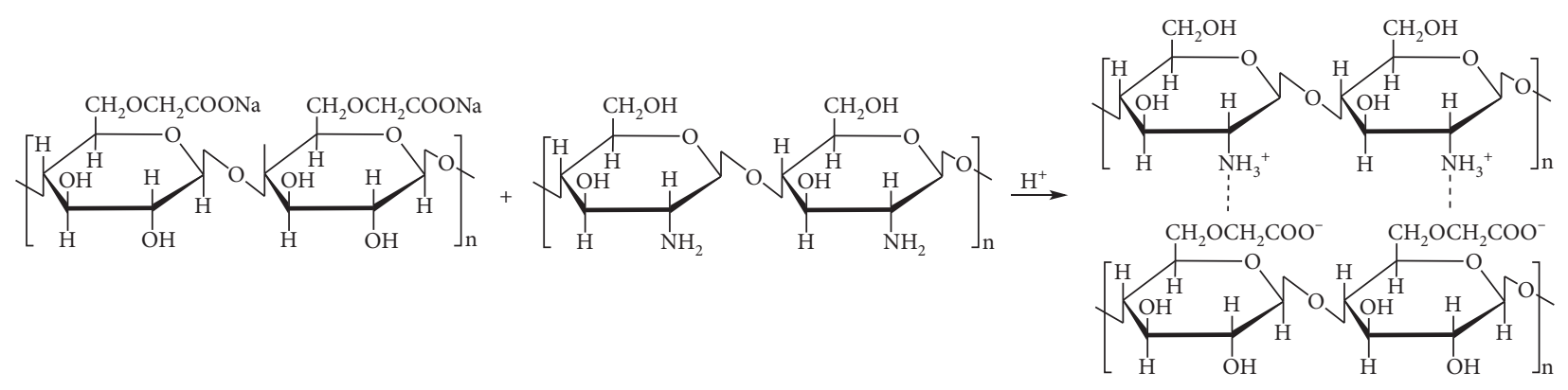

(a)

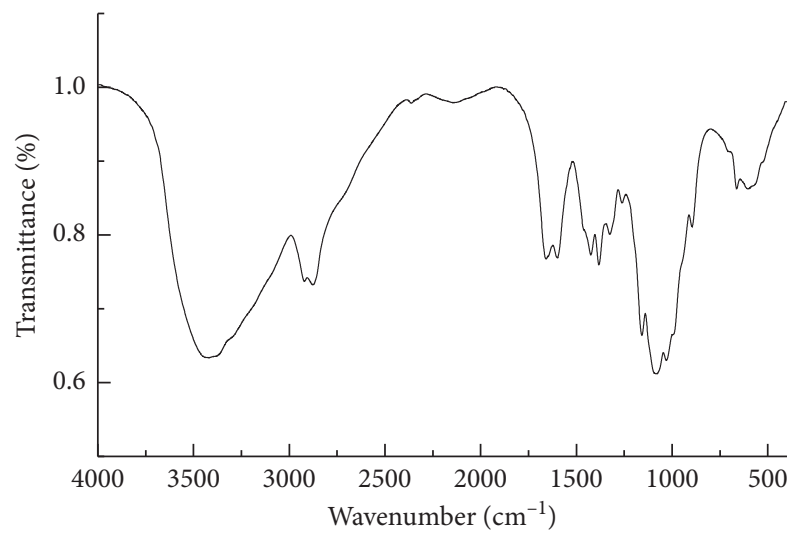

(b)

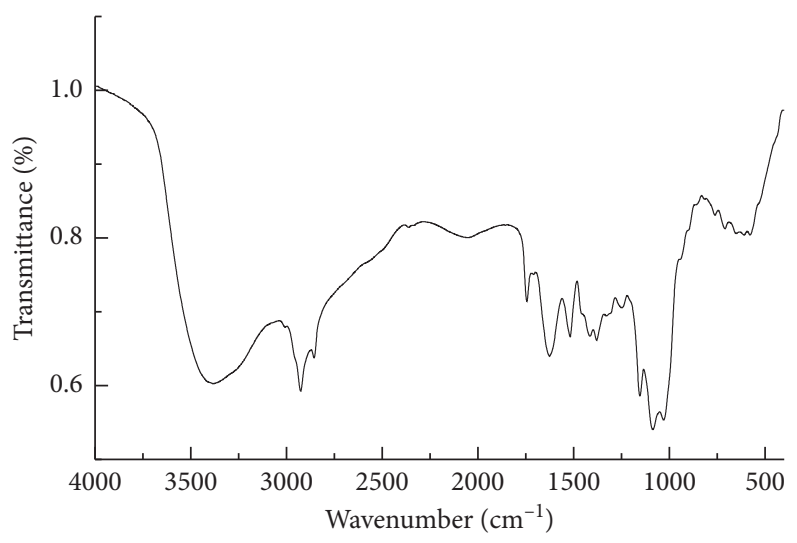

(c)

Figure 2: Crosslinking structure (a) and FTIR spectra of chitosan (b) and chitosan-CMC LBL assembly (c).

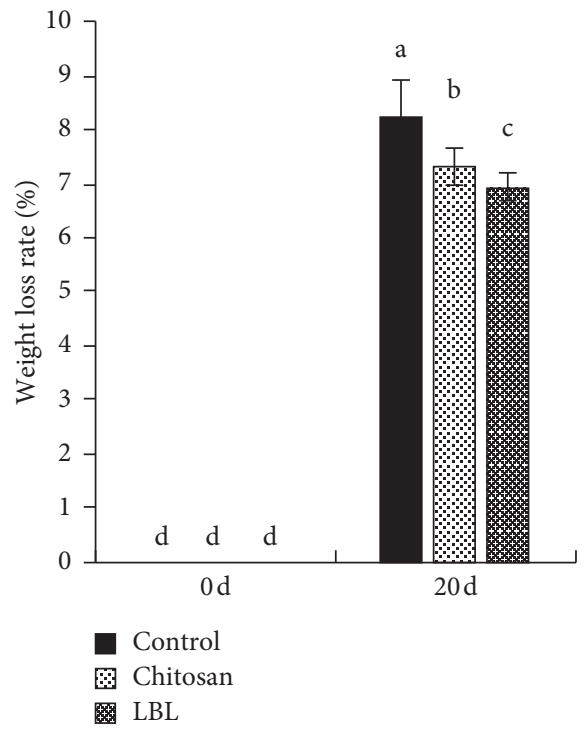

(a)

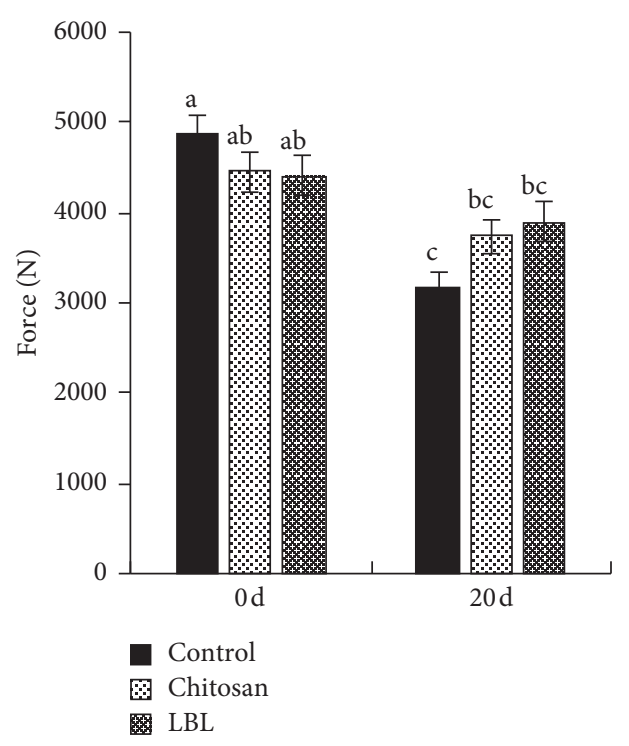

(b)

FIgURE 3: Continued. 


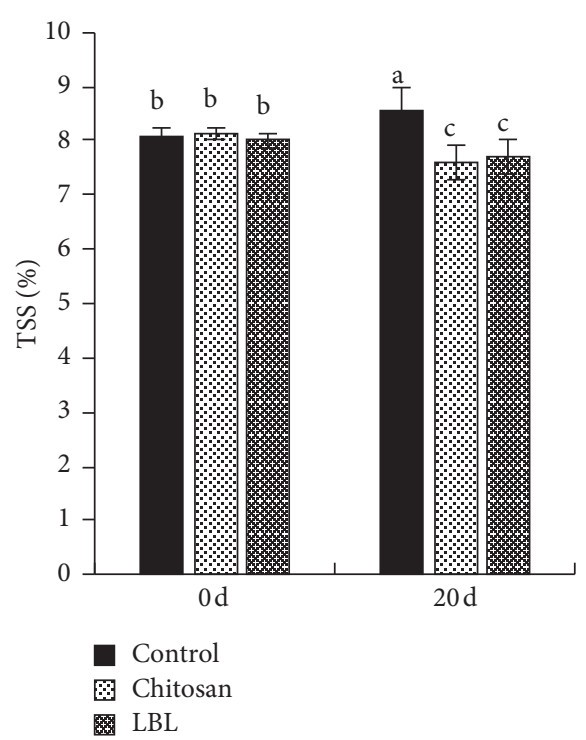

(c)

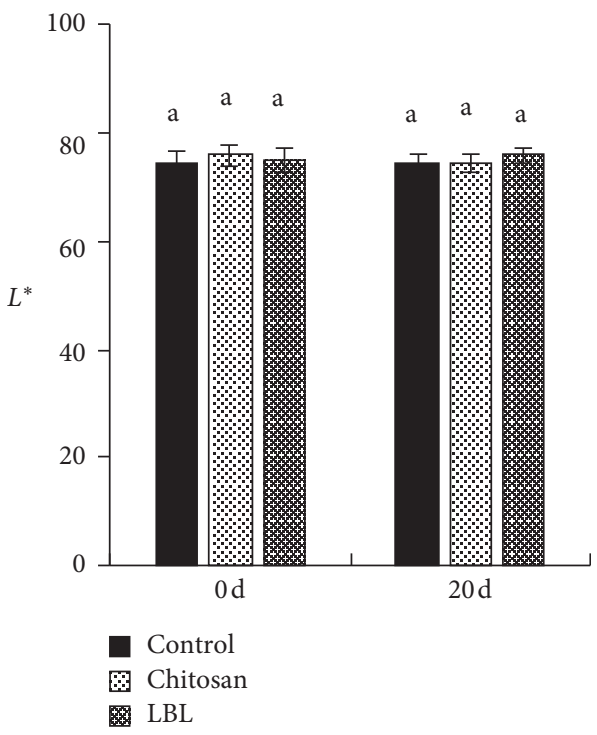

(e)

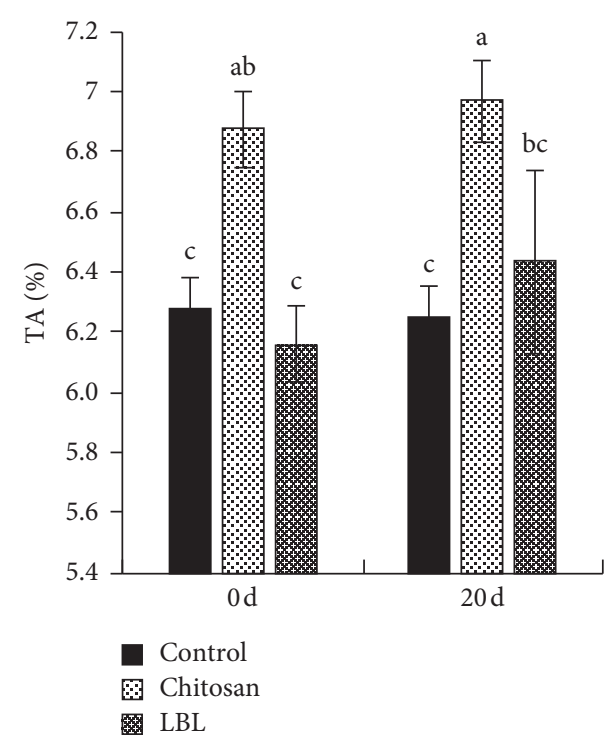

(d)

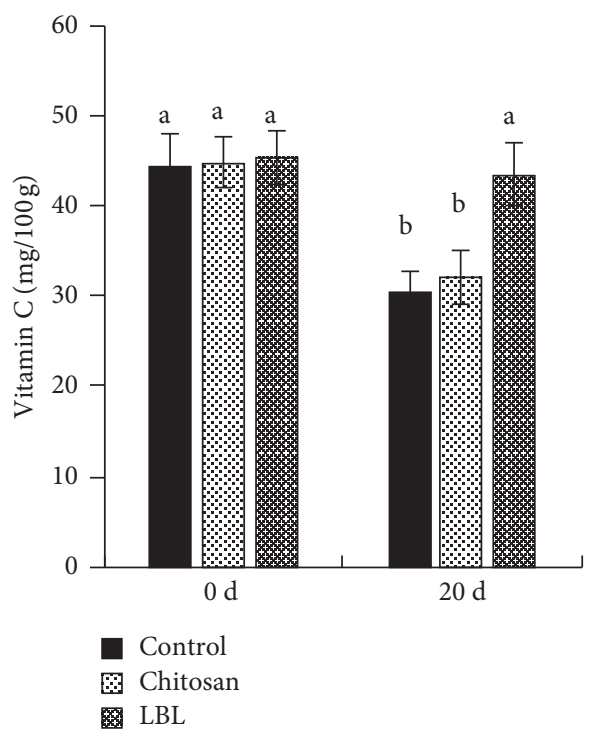

(f)

Figure 3: Weight loss (a), firmness (b), TSS (c), TA (d), $L^{*}$ value (e), and vitamin C content (f) of lemon fruits before and after storage.

the TSS content of strawberry and citrus fruit by Arnon et al. [27]. Additionally, TA mainly refers to the organic acid in the lemon fruit and TA content could affect the acidity and taste related to fruit ripening and senescence. It could be proved from Figure 3(d) that the content of lemon TA in the chitosan group was significantly higher than that in the other two groups, both before and after storage, indicating that the difference was caused by the significant inhibition of the organic acid decomposition of the lemon fruit $(p<0.05)$. It was also previously reported that the chitosan coating had significant effect on the TA content of papaya [29], grape, and strawberry by delaying the rate of TA decline [30]. Results indicated that the chitosan-CMC significantly increased the TA content, in comparison to chitosan and control groups, which provided further evidence that the
LBL assembly beneficially maintained lemon taste quality after storage.

The color of the lemon peel can be used as a criterion for the evaluation of fruit ripeness and senescence during commercial storage and transportation. The $L^{*}$ value indicated the brightness and freshness of the lemon peel. In the present study, there was no significant difference in the brightness of the lemon between the coating treatment and the control group, according to the Figure 3(e), while the chitosan-CMC LBL assembly did not significantly injure the fruit gloss and overall visual appearance $(p>0.05)$.

Another quality attribute, the vitamin $\mathrm{C}$ content, has strong reducing ability and belongs to the important nonenzymatic active oxygen scavenging system in the fresh produce. It functions in free radical scavenging and 


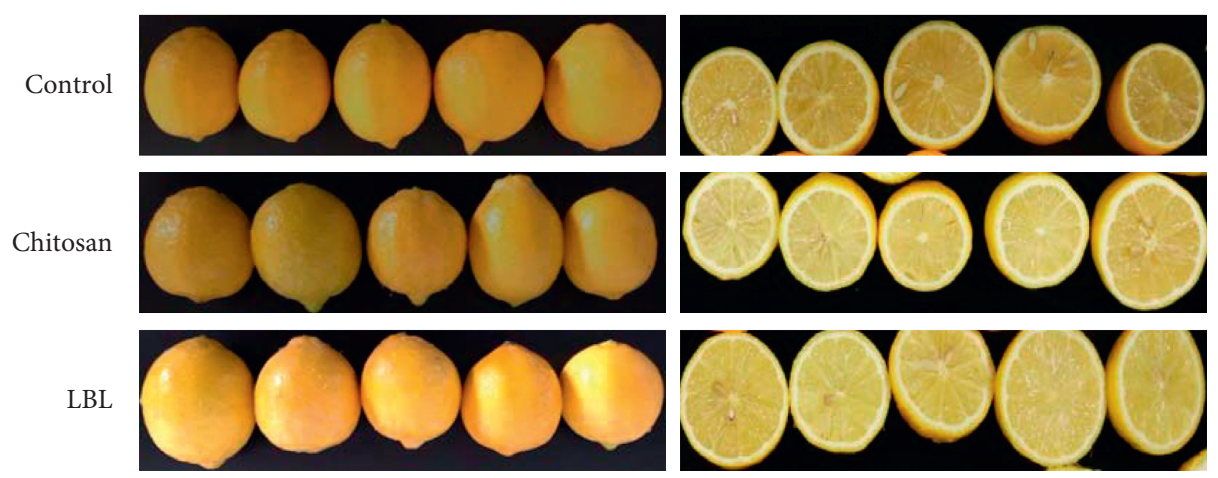

(a)

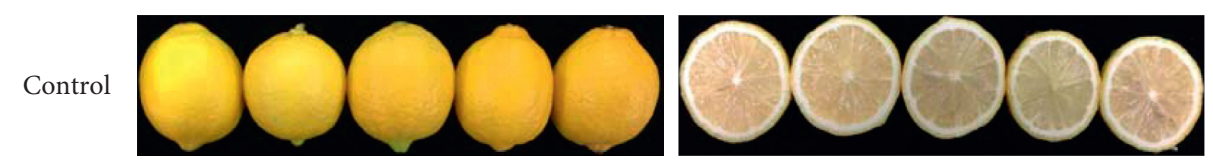

Chitosan

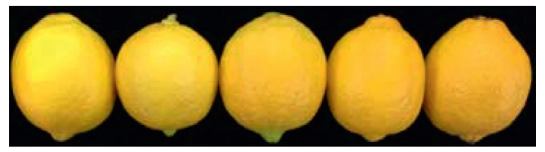

LBL
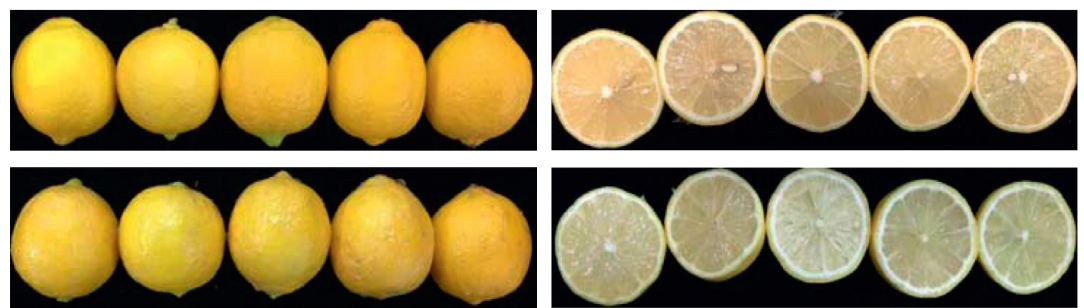

(b)

Figure 4: Morphology of lemon fruits before (a) and after storage (b).

Control

Chitosan

LBL

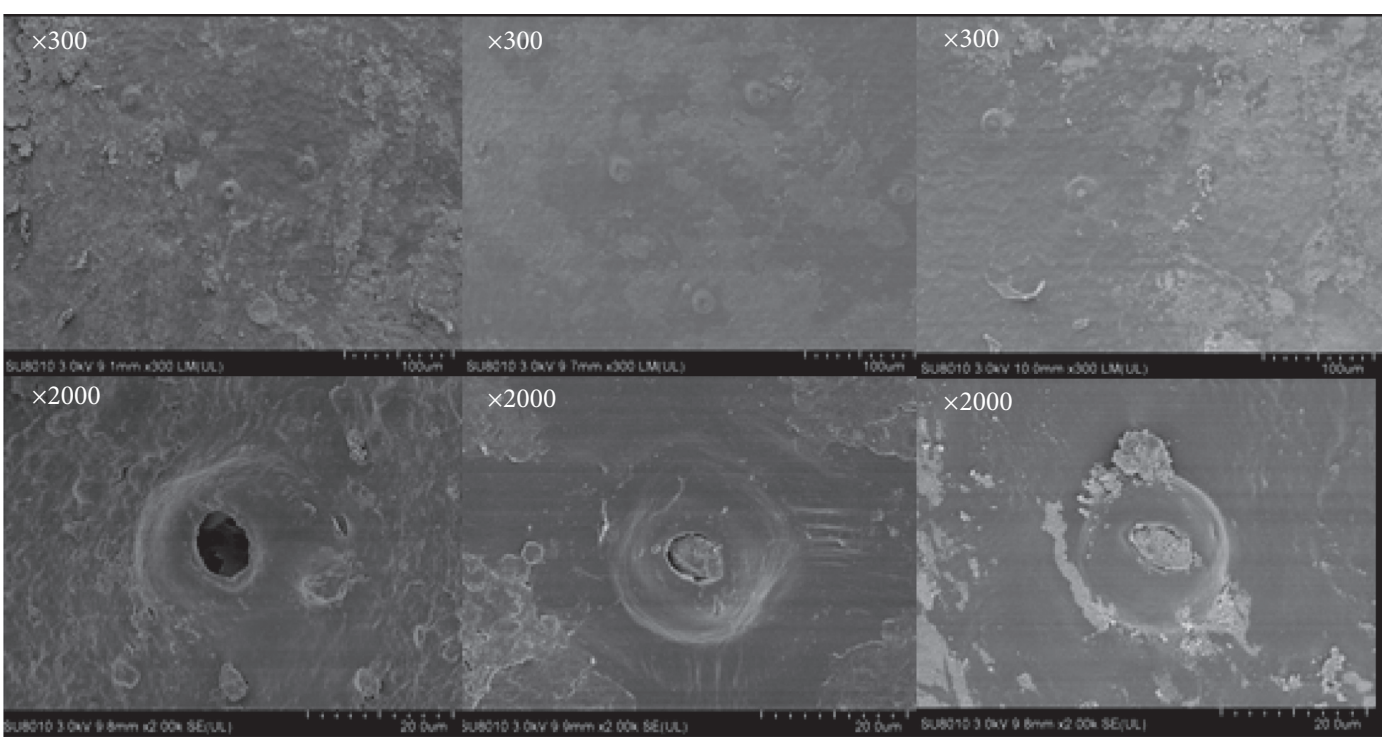

(a)

Figure 5: Continued. 


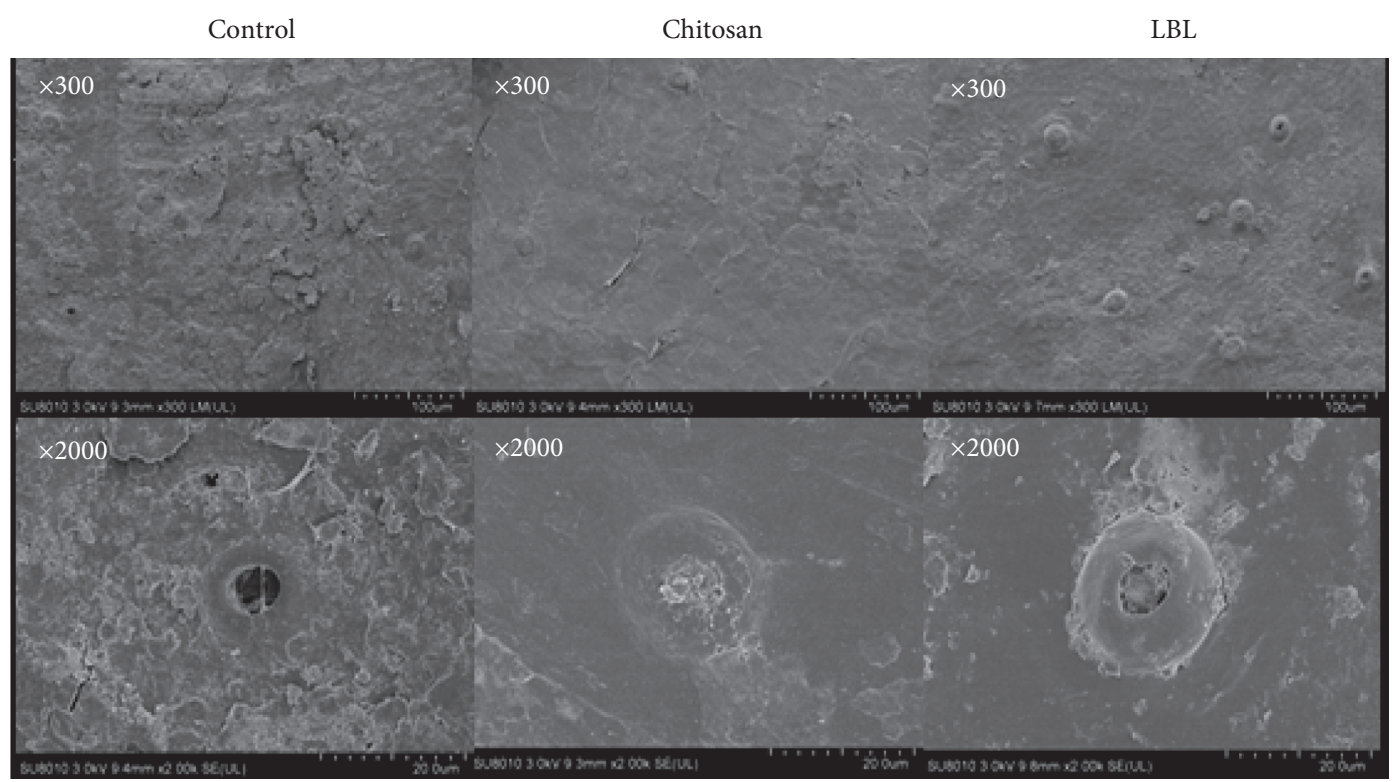

(b)

Figure 5: SEM images of lemon fruits before (a) and after storage (b).

antioxidation, involving in the delay of lemon senescence. In the present study, there was no significant difference in the original vitamin $\mathrm{C}$ content of the three groups in the initial storage period $(p>0.05)$. After storage, the vitamin $C$ content was significantly elevated by the LBL assembly, followed by chitosan monolayer coating $(p<0.05$, Figure 3(f)), which improved the antioxidation capacity during lemon senescence process. This is consistent with the results of the longan fruit coated by the chitosan composite [31].

3.3. Lemon Morphology and Microstructure. Results of the lemon morphology clearly demonstrated that the edible coating, especially the chitosan-CMC layer-by-layer assembly significantly inhibited the flesh browning, while maintaining the surface glossiness and visual appearance of the lemon fruit after storage $(p<0.05$, Figure 4$)$. The SEM images of the lemon microstructure indicated that the exogenous coating affected the size and number of stomata in the lemon epidermis (Figure 5). The stomata is the channel of the air and water vapor exchange from the fresh lemon and is the invasion site of the pathogen; the opening and closing action of the stomata in the guarding cell is involved in the regulations of carbon assimilation, respiration, and transpiration. It was clearly shown that both chitosan monolayer and chitosan-CMC LBL assembly reduced the number and the opening of stomata, thus contributing to the transpiration inhibition and senescence delay of the lemon fruit. Results in the present study revealed that the LBL assembly tremendously enhanced the fruit barrier and protection against abiotic and biotic stress stimuli.

\section{Conclusions}

This study developed a novel chitosan-CMC layer-by-layer deposition assembly, which exhibited excellent water vapor permeability, puncture strength, and elasticity properties (1.25-1.74 times greater than that of chitosan). The research provides substantial evidence to support the hypothesis that the LBL assembly maintained the lemon quality, such as fruit firmness and vitamin $\mathrm{C}$ content, during storage at $0^{\circ} \mathrm{C}$ for 20 days. These findings provide an alternative route to maintain quality and postponing senescence of the postharvest fresh produce. The methodology and procedure proposed in the present study need to be further confirmed in dependence of the polymer concentrations and fruit cultivars.

\section{Data Availability}

The data used to support the findings of this study are included within the article.

\section{Conflicts of Interest}

The authors declare that there are no conflicts of interest regarding the publication of this paper.

\section{Authors' Contributions}

Fangyuan Chen and Jinglin Zhang contributed equally to this work.

\section{Acknowledgments}

This research was funded by the Zhejiang Public Welfare Technology Research Project (Grant no. LGN18C200022), the China Postdoctoral Science Foundation (Grant no. 2018M641659), the Science Foundation Project of Zhejiang University of Science and Technology (Grant no. 2019QN21, 2019JL03), and the Opening Fund of Key Laboratory of Ministry of Agriculture and Rural Affairs (Grant no. KLAPPH2-2017-07). 


\section{References}

[1] A. Vass, E. Korpics, and M. Dernovics, "Follow-up of the fate of imazalil from post-harvest lemon surface treatment to a baking experiment," Food Additives \& Contaminants: Part A, vol. 32, no. 11, pp. 1875-1884, 2015.

[2] R. K. Dhall, "Advances in edible coatings for fresh fruits and vegetables: a review," Critical Reviews in Food Science and Nutrition, vol. 53, no. 5, pp. 435-450, 2013.

[3] H. Arnon, R. Granit, R. Porat, and E. Poverenov, "Development of polysaccharides-based edible coatings for citrus fruits: a layer-by-layer approach," Food Chemistry, vol. 166, pp. 465-472, 2015.

[4] S. X. Wang, N. Yousefi, and N. Tufenkji, "Self-assembly of ultralarge graphene oxide nanosheets and alginate into layered nanocomposites for robust packaging materials," ACS Applied Nano Materials, vol. 2, no. 3, pp. 1431-1444, 2019.

[5] L. Cseri and G. Szekely, "Towards cleaner PolarClean: efficient synthesis and extended applications of the polar aprotic solvent methyl 5-(dimethylamino)-2-methyl-5-oxopentanoate," Green Chemistry, vol. 21, no. 15, pp. 4178-4188, 2019.

[6] H. A. L. Phuong, N. A. I. Ayob, C. F. Blanford, N. F. M. Rawi, and G. Szekely, "Nonwoven membrane supports from renewable resources: bamboo fiber reinforced poly(lactic acid) composites," ACS Sustainable Chemistry \& Engineering, vol. 7, no. 13, pp. 11885-11893, 2019.

[7] K. L. Stinson-Bagby, J. Owens, A. Rouffa, M. J. Bortner, and E. J. Foster, "Silver nanoparticle pulsed synthesis and attachment to cellulose nanocrystals," ACS Applied Nano Materials, vol. 2, no. 4, pp. 2317-2324, 2019.

[8] T. Marino, F. Russo, A. Criscuoli, and A. Figoli, "TamiSolve NxG as novel solvent for polymeric membrane preparation," Journal of Membrane Science, vol. 542, no. 15, pp. 418-429, 2017.

[9] D. Zhao, J. F. Kim, G. Ignacz, P. Pogany, Y. M. Lee, and G. Szekely, "Bio-inspired robust membranes nanoengineered from interpenetrating polymer networks of polybenzimidazole/polydopamine," ACS Nano, vol. 13, no. 1, pp. 125-133, 2019.

[10] I. Banerjee, R. C. Pangule, and R. S. Kane, "Antifouling coatings: recent developments in the design of surfaces that prevent fouling by proteins, bacteria, and marine organisms," Advanced Materials, vol. 23, no. 6, pp. 690-718, 2011.

[11] M. Z. Elsabee and E. S. Abdou, "Chitosan based edible films and coatings: a review," Materials Science and Engineering: $C$, vol. 33, no. 4, pp. 1819-1841, 2013.

[12] X. Zhang, G. Xiao, Y. Wang, Y. Zhao, H. Su, and T. Tan, "Preparation of chitosan- $\mathrm{TiO}_{2}$ composite film with efficient antimicrobial activities under visible light for food packaging applications," Carbohydrate Polymers, vol. 169, pp. 101-107, 2017.

[13] P. K. Dutta, S. Tripathi, G. K. Mehrotra, and J. Dutta, "Perspectives for chitosan based antimicrobial films in food applications," Food Chemistry, vol. 114, no. 4, pp. 1173-1182, 2009.

[14] Q. Wang, J. Zhang, and A. Wang, "Preparation and characterization of a novel pH-sensitive chitosan-g-poly (acrylic acid)/attapulgite/sodium alginate composite hydrogel bead for controlled release of diclofenac sodium," Carbohydrate Polymers, vol. 78, no. 4, pp. 731-737, 2009.

[15] J. J. Richardson, M. Bjornmalm, and F. Caruso, "Technologydriven layer-by-layer assembly of nanofilms," Science, vol. 348, no. 6233, p. aaa2491, 2015.
[16] P. Lavalle, J.-C. Voegel, D. Vautier, B. Senger, P. Schaaf, and V. Ball, "Dynamic aspects of films prepared by a sequential deposition of species: perspectives for smart and responsive materials," Advanced Materials, vol. 23, no. 10, pp. 1191-1221, 2011.

[17] R. Porat, B. Weiss, L. Cohen, A. Daus, and A. Biton, "Effects of polyethylene wax content and composition on taste, quality, and emission of off-flavor volatiles in 'Mor' mandarins," Postharvest Biology and Technology, vol. 38, no. 3, pp. 262268, 2005.

[18] B. G. de S. Medeiros, A. C. Pinheiro, M. G. Carneiro-daCunha, and A. A. Vicente, "Development and characterization of a nanomultilayer coating of pectin and chitosan-evaluation of its gas barrier properties and application on 'Tommy Atkins' mangoes," Journal of Food Engineering, vol. 110, no. 3, pp. 457-464, 2012.

[19] I. M. Brasil, C. Gomes, A. Puerta-Gomez, M. E. Castell-Perez, and R. G. Moreira, "Polysaccharide-based multilayered antimicrobial edible coating enhances quality of fresh-cut papaya," LWT-Food Science and Technology, vol. 47, no. 1, pp. 39-45, 2012.

[20] E. Poverenov, S. Danino, B. Horev, R. Granit, Y. Vinokur, and V. Rodov, "Layer-by-Layer electrostatic deposition of edible coating on fresh cut melon model: anticipated and unexpected effects of alginate-chitosan combination," Food and Bioprocess Technology, vol. 7, no. 5, pp. 1424-1432, 2013.

[21] J. M. Fernández-Ginés, J. Fernández-López, E. Sayas-Barberá, E. Sendra, and J. A. Pérez-Álvarez, "Lemon albedo as a new source of dietary fiber: application to bologna sausages," Meat Science, vol. 67, no. 1, pp. 7-13, 2004.

[22] E. González-Molina, R. Domínguez-Perles, D. A. Moreno, and C. García-Viguera, "Natural bioactive compounds of Citrus limon for food and health," Journal of Pharmaceutical and Biomedical Analysis, vol. 51, no. 2, pp. 327-345, 2010.

[23] C. Wasternack and M. Strnad, "Jasmonate signaling in plant stress responses and development-active and inactive compounds," New Biotechnology, vol. 33, no. 5, pp. 604-613, 2016.

[24] G. Oboh, F. O. Bello, A. O. Ademosun, A. J. Akinyemi, and T. M. Adewuni, "Antioxidant, hypolipidemic, and anti-angiotensin-1-converting enzyme properties of lemon (Citrus limon) and lime (Citrus aurantifolia) juices," Comparative Clinical Pathology, vol. 24, no. 6, pp. 1395-1406, 2015.

[25] L. Palou, S. Valencia-Chamorro, and M. Pérez-Gago, "Antifungal edible coatings for fresh citrus fruit: a review," Coatings, vol. 5, no. 4, pp. 962-986, 2015.

[26] E. Poverenov, R. Rutenberg, S. Danino, B. Horev, and V. Rodov, "Gelatin-chitosan composite films and edible coatings to enhance the quality of food products: layer-bylayer vs. blended formulations," Food and Bioprocess Technology, vol. 7, no. 11, pp. 3319-3327, 2014.

[27] H. Arnon, Y. Zaitsev, R. Porat, and E. Poverenov, "Effects of carboxymethyl cellulose and chitosan bilayer edible coating on postharvest quality of citrus fruit," Postharvest Biology and Technology, vol. 87, pp. 21-26, 2014.

[28] X. Liu, W. Han, Y. Zhu et al., "Anti-oxidative and antibacterial self-healing edible polyelectrolyte multilayer film in fresh-cut fruits," Journal of Nanoscience and Nanotechnology, vol. 18, no. 4, pp. 2592-2600, 2018.

[29] A. Ali, M. T. M. Muhammad, K. Sijam, and Y. Siddiqui, "Effect of chitosan coatings on the physicochemical characteristics of Eksotika II papaya (Carica papaya L.) fruit during cold storage," Food Chemistry, vol. 124, no. 2, pp. 620-626, 2011. 
[30] H. T. Au, L. N. Pham, T. H. T. Vu, and J. S. Park, "Fabrication of an antibacterial non-woven mat of a poly(lactic acid)/ chitosan blend by electrospinning," Macromolecular Research, vol. 20, no. 1, pp. 51-58, 2011.

[31] S. Shi, W. Wang, L. Liu, S. Wu, Y. Wei, and W. Li, "Effect of chitosan/nano-silica coating on the physicochemical characteristics of longan fruit under ambient temperature," Journal of Food Engineering, vol. 118, no. 1, pp. 125-131, 2013. 